\title{
Diet and health in Central-Southern Italy during the Roman Imperial time
}

\author{
Luca Bondioli ${ }^{1}$, Alessia Nava ${ }^{1,2}$, Paola Francesca Rossi ${ }^{1}$, Alessandra Sperduti ${ }^{1,3}$ \\ ${ }^{1}$ Section of Bioarchaeology, National Museum of Prehistory and Ethnography "Luigi Pigorini", Polo Museale del Lazio, P.zza Marconi 14, \\ 00144 Rome, Italy \\ ${ }^{2}$ Department of Environmental Biology, Sapienza University of Rome, P.le Aldo Moro 5, 00185 Rome, Italy \\ ${ }^{3}$ University of Naples "L'Orientale", P.zza San Domenico Maggiore 12, 80134 Naples, Italy
}

\section{ABSTRACT}

The reconstruction of ancient diets by means of stable isotopes analysis acquires a deeper meaning when their results are compared with other odonto-skeletal indicators which are strongly contextualized in the light of historical and archaeological evidence. Nevertheless, the outcomes can be contradictory or, more realistically, they may not completely satisfy our hypotheses on how complex and diverse conditions - such as health status, life style, diet and nutrition - can actually interrelate in the life course of an individual.

In this study we present and discuss evidences from Isola Sacra and Velia, two Roman Imperial Age coastal towns. The $\delta^{15} \mathrm{~N}$ and $\delta^{13} \mathrm{C}$ values are compared with demographic and health status parameters, such as age, sex, stature, auricular exostoses, DISH, cribra orbitalia, enamel defects.

\section{Section: RESEARCH PAPER}

Keywords: Roman imperial time; diet and health; Carbon and Nitrogen isotopes

Citation: Luca Bondioli, Alessia Nava, Paola Francesca Rossi, Alessandra Sperduti, Diet and health in central-southern Italy during the roman Imperial time, Acta IMEKO, vol. 5, no. 2, article 4, September 2016, identifier: IMEKO-ACTA-05 (2016)-02-04

Section Editors: Sabrina Grassini, Politecnico di Torino, Italy; Alfonso Santoriello, Università di Salerno, Italy

Received March 15, 2016; In final form April 7, 2016; Published September 2016

Copyright: (C) 2016 IMEKO. This is an open-access article distributed under the terms of the Creative Commons Attribution 3.0 License, which permits unrestricted use, distribution, and reproduction in any medium, provided the original author and source are credited

Funding: Ministero dei beni e delle attività culturali e del turismo, Italy

Corresponding author: Luca Bondioli, e-mail: luca.bondioli@beniculturali.it

\section{INTRODUCTION}

The study of the funerary complexes is always and necessarily accompanied by the analysis of human bones and teeth. A fruitful relationship between the two areas of research was in fact established through dialogue and collaboration both on the field as in the laboratory - and led to significant advances in the historical reconstruction of the biocultural dynamics that characterized the evolution of human populations in space and time. The final outcome is the attempt to provide a consistent response to the growing demand, by archaeologists and historians, of coherent reconstructions of past adaptations to the environment.

Skeletal anthropology has matured, since the immediate post-war period, its own disciplinary status, which takes advantage of the development of advanced technologies and methods of investigation. Nevertheless, the reconstruction of biological adaptations of past populations, based on odontoskeletal remains, is extremely difficult and complex. This difficulty is even more evident when approaching the subject of dietary and health status reconstructions in the highly stratified Roman Imperial society.

The study of biocultural adaptation scenarios of ancient populations has, in fact, proved to be a difficult challenge. Indeed, the validity of the mortality models based on skeletal analyses was deeply criticized by the contributions of Boquet and Masset [1] and Wood and associates [2], who undermined the reconstructive power of paleodemographic and health status indicators in the odontoskeletal record. Fortunately, over twenty years after the publication of these basic critical tools, skeletal anthropology is consistently increasing the quantity and especially the quality of the information today extractable from skeletal populations. This contribution illustrates the usefulness 
of collagen Carbon and Nitrogen isotopic composition studies as proxy of ancient diet. The data from two major Italian coastal communities of Roman times are used not only to reconstruct diet, but are analysed in the framework of the morphological, histological and paleopathological evidences, opening unexpected interpretive opportunities.

\section{MATERIALS AND METHODS}

\subsection{The skeletal material from Isola Sacra and Velia}

The two skeletal series come from the Roman Imperial necropolises of Isola Sacra (Lazio, I-III cent. AD) and VeliaPorta Marina (Campania, I-II cent. AD) (Figure 1). Isola Sacra has been the main necropolis of the harbor town of Portus Romae, serving the capital of the empire. The several excavation campaigns have yielded more than 2000 skeletal individuals. Porta Marina was the southern gate graveyard of Velia, a port town on the Tyrrhenian Sea. More than 300 skeletons were recovered. The high level of preservation and completeness of both skeletal collections has allowed an extensive and highly standardized data recording. In this study the isotopic individual data, available for 117 individuals from Velia and 105 individuals from Isola Sacra, are crossed with other anthropological data.

\subsection{Sex and age-at-death diagnosis}

When dealing with well represented skeletal individuals, sex estimates can reach high levels of consistency. Sexing on the base of skull and pelvis morphology gives $98 \%$ of correct diagnosis [3]. A recent study has demonstrated a similar discriminative power in the application of univariate and multivariate methods on long bones [4].

The level of reliability of the several aging techniques proposed in literature has been questioned and tested in numerous anthropological studies. The most critical contribution [1] pointed out that skeletal age-at-death estimates tend to mimic the age distribution of the reference sample from which the criteria were developed. This issue can be partly

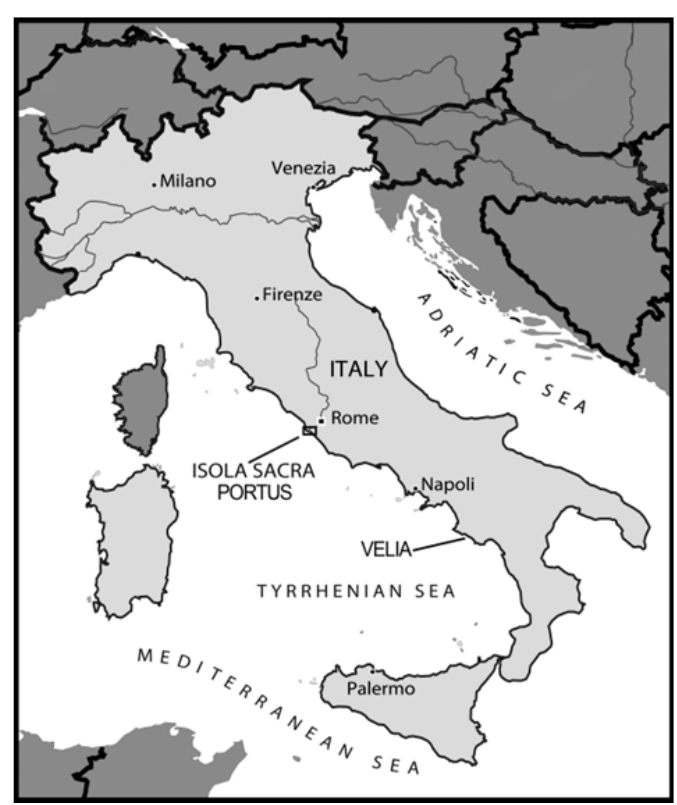

Figure 1. Geographic location of the port towns of Portus Romae and Velia Porta Marina. overcome by employing procedures such as the "combined" method [5], the summary age method [6] and the transition analysis [7]. Another important issue is the level of consistency among researchers and across laboratories [8]-[10].

In this study, the analyses for sex and age-at-death assessments were performed following the criteria commonly reported in literature [3], [11], [12]. Sex was mainly diagnosed on the basis of the morphology of the pelvis and the skull. Age at death of adults individuals was estimated by means of many odontoskeletal indicators, which included, among others, degenerative changes of the pubic symphysis and auricular surface of the pelvis; morphological variation of the sternal end of the $4^{\text {th }}$ rib, dental wear and ecto- and endocranial suture closure. The subadults were aged according to dental formation and eruption stages [13] and skeletal maturity and dimensions [14].

In our age at-death assessment we followed the approach of the combined method in order to minimize the "reference sample effect". We also tested, in the Velia series, the intraobserver level of consistency. A subsample of 241 skeletal individuals was aged by two researchers separately. The level of agreement reaches $88.8 \%$, while in the remaining cases the discordance never exceeded one age class. As expected, the inter-observer error was very low for subadults $(5.8 \%$ of the total estimates) in comparison with the adults ( $>20$ years 18.6 $\%$. The cases of discrepancy have been resolved with an additional assessment performed by a third observer, and using wider age classes.

\subsection{Stature}

Adult stature estimation can be considered as a rather good descriptive of the life conditions of a population because, beyond the direct action of the genetic pool, is strongly influenced by the health status and diet during early life [15]. Estimation of stature in archaeological samples relies on linear regression formulae derived from reference collections that correlate the length of long bones (femur, tibia, fibula, humerus, radius, ulna) with living stature (i.e. [16]-[19]). The choice of the most proper regression formula to be used is crucial: the equations available in the literature are calibrated on specific modern population samples and the body proportions of the archaeological sample should be consistent with that of the reference one [20]. As suggested by Giannecchini and MoggiCecchi [21], the Pearson's regression formulae are the most reliable for Italian historical samples, thus adult living stature in our Roman Italian coastal population was calculated applying this regression method.

The maximum length for each bone, with no regard about side, was measured following the standard technique by Martin and Saller [22]. For each individual, the length of all the available long bones (considering femur, tibia, humerus, radius) was measured and the stature was given as the mean value of all the obtainable estimates.

\subsection{Pathological assessments}

In the last decades, paleopathology has undergone a significant shift from descriptive analysis on individual cases to a population-based epidemiological perspective. The quantification and the cross comparison of past population health status present problems of diagnosis and interpretation [2], [23]-[25], which correlate with the standardization of the scoring methods and with inter-observer consistency [26], [27]. Finally, the paleopathological practice has to deal with the 
continuum model of pathological skeletal signs and the issue of how to better ascribe the progressive manifestations to clear-cut discrete categories.

In our study, the following macroscopic health indicators were recorded: cribra orbitalia; enamel hypoplasia; diffuse idiopathic hyperostosis (DISH), external auricular exostosis (EAE). All the health indicators were systematically recorded for the whole sample. The general guidelines for diagnosis and assessment of the pathological changes are reported in Buikstra and Ubelaker [11] and Grauer [28]. DISH was positively diagnosed by the pathognomonic features of the vertebral column; i.e. the ossification of the anterior longitudinal ligaments of the spine. Enamel hypoplasic defects on teeth were counted and chronologically assessed by measuring their relative position from the cervical line (cemento-enamel junction) [29]. A 4 grade recording system was used in the assessment of presence and severity of cribra orbitalia, according to Buikstra and Ubelaker [11]; while the recording of external auricular exostosis followed the method presented in Crowe and colleagues [30].

\subsection{Dental enamel histology}

Histomorphometrical analysis of tooth crowns allows enhancing and interpreting enamel microstructures that are formed during amelogenesis (i.e. weekly Retzius lines and daily cross striations [31]) as result of the regular periodicity of enamel matrix secretion. A physiological stress event strong enough to temporary disrupt amelogenesis, causes an abrupt change in the orientation of the enamel prisms, visible in an histological thin section as a broad dark band (Accentuated Retzius Line (ARL) or Wilson band [32]). Thus using the long and short period markings of enamel formation, it is possible to reconstruct the temporal scales of stress event chronology. The scale is zeroed at birth, marked by the first Accentuated stria, the Neonatal Line [33], [34].

To establish the chronology of the stress events in the deciduous teeth the regression formulas proposed by Birch and Dean [35] were used, while for the first permanent molars the method by Guatelli-Steinberg and collaborators [36] has been applied, based on the average daily rate of enamel secretion (about $2.85 \mu \mathrm{m}$ per day) within $200 \mu \mathrm{m}$ from the Enamel Dentine Junction. Starting from the tip of the dentine horn and following an enamel prism toward the outer surface, the first ARL was detected and the corresponding length was measured. The same procedure was applied to all the ARL encountered in the lateral enamel moving toward the tooth neck. The regression formulas transform distances in days of enamel formation.

This methodology has been used to determine with a daily accuracy the age at death of immature individuals in a subsample from Velia, presenting the Neonatal Line and the crown still forming at the time of death.

Thin sections of dental crowns were obtained using the method proposed by Caropreso and colleagues [37]. The teeth, after an ultrasonic bath, were included in bicomponent epoxy resin (Epofix Buehler) and cut in longitudinal buccolingual sections by means of a diamond blade microtome (Leica Microtome Diamond Blade 1600, Leica AG). Each section was thinned with abrasive paper mounted on a motorized grinder in distilled water (Minimet 1000 Automatic Polishing Machine, Buehler) up to about $100 \mu \mathrm{m}$. Further polishing with alumina powder (0.05 $\mu \mathrm{m}$ gamma alumina Micropolish B, Buehler) allowed the elimination of the cutting marks and the enhancement of the features of the fine structure of the enamel. After assembling the cover glass, each thin section was digitally recorded through a camera (Leica DFC 295) attached to an optical microscope (Laborlux S, Leica AG) under polarized light, with the magnification of $40 \times$ (resolution $1600 \times 1200$ pixels). To digitally analyze the images, each crown was reconstructed assembling overlapping pictures using dedicated software (Fiji - plugin Mosaic j, [38]).

\subsection{Isotopes analyses}

The isotopes analyses for diet reconstruction were previously performed and published [39]-[41]. Full details of the sampling and analytical methodologies, as well as individual data, are given in the above mentioned studies.

\section{RESULTS AND DISCUSSION}

\section{1. $\delta^{15} \mathrm{~N}$ and $\delta^{13} \mathrm{C}$ values of Isola Sacra and Velia}

The diet composition of Velia and Isola Sacra, compared with data available in literature for the Roman Empire, is presented in Figure 2. The two samples under study are characterized by a high intra-site variability. For $\delta^{15} \mathrm{~N}$, in fact, the values show the coexistence of both low and high protein intake diets, the latter possibly deriving from marine food.

As already suggested in [39]-[41], males tend to consume more high trophic foods (meat and/or fish) than females (Figure 3), even if this tendency is statistically significant in Velia but not in Isola Sacra.

\subsection{Velia: diet and stature}

Adult stature, although being a multifactorial trait influenced by a complex interplay of genetic and environmental factors, is commonly used as a proxy for health and nutritional status during growth [15]. The relationship between stature and diet composition for Velia is presented in Figure 4. Results show a positive correlation between individual height and $\delta^{15} \mathrm{~N}$ values, reaching the significance only in the male series (generalized additive regression model, $\mathrm{p}=0.022$ ).

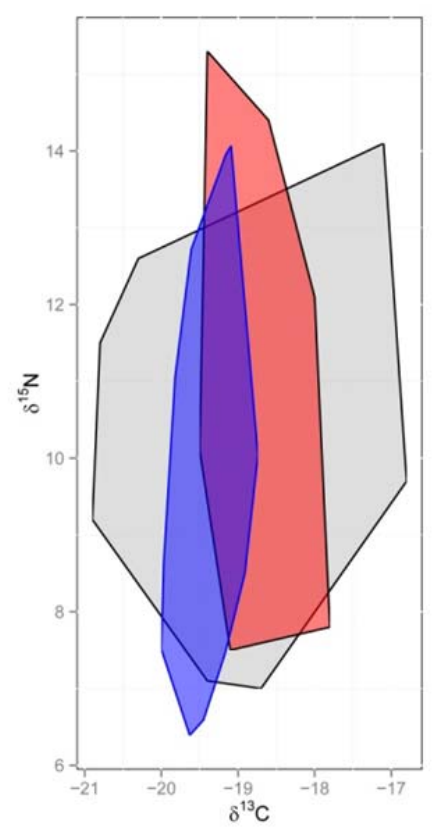

Figure 2. Plot of convex hulls of the $\delta^{15} \mathrm{~N}$ and $\delta^{13} \mathrm{C}$ individual values in Velia (blue), Isola Sacra (red) and other Roman Imperial Age skeletal series (grey). 


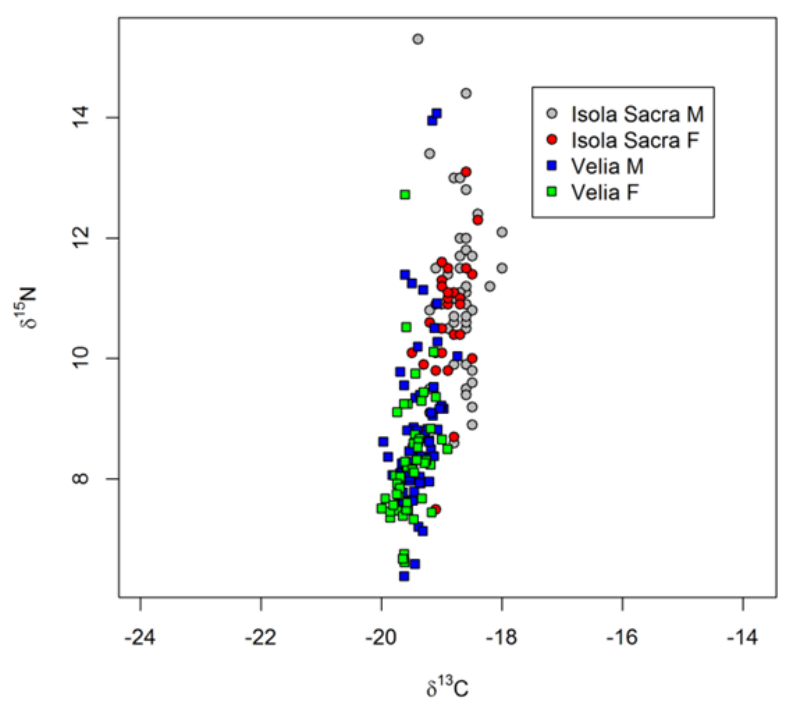

Figure 3. $\delta^{15} \mathrm{~N}$ and $\delta^{13} \mathrm{C}$ values in Velia and Isola Sacra by sex.

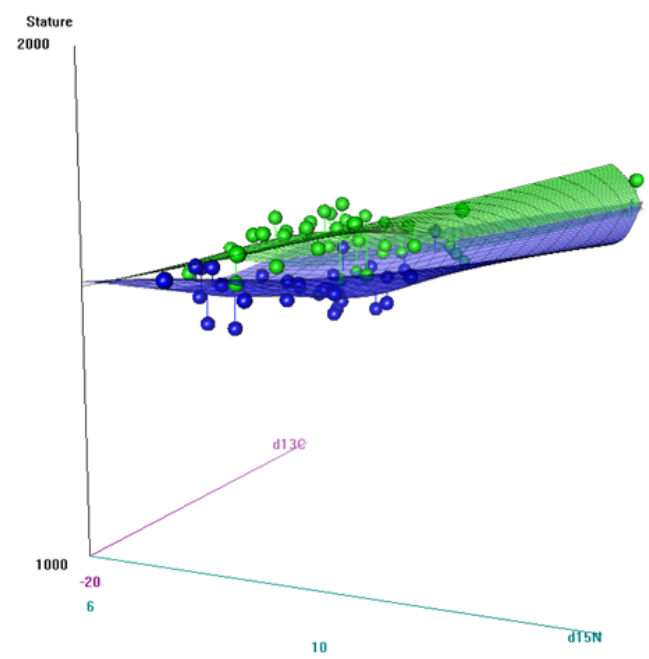

Figure 4. 3D scatterplot and generalized additive regression of stature in males (green dots) and female (blue dots) of Velia in reference to $\mathrm{N}$ and $\mathrm{C}$ isotopic ratios.

\subsection{Velia and Isola Sacra: diet and auricular exostosis}

External auricular exostosis (EAE) is an abnormal bony growth within the external ear meatus that has proved to be very informative in detecting aquatic working activities in past populations [40]. The frequency of EAE in Isola Sacra and Velia adult males is rather high $(21.1 \%$ and $35.3 \%$, respectively). The presence of this specific occupational marker is significantly higher among the marine food consumers in Velia, as shown in Figure 5. Conversely, at Isola Sacra, the correlation between EAE and the $\mathrm{C}, \mathrm{N}$ isotopic ratio fails to be significantly different from zero.

\subsection{Velia: diet and cribra orbitalia}

Cribra orbitalia is a pathological lesion consisting of porosities in the outer table of the orbital roof. It is mainly linked to iron deficiency anemia, of acquired (unbalanced diets, diarrheal disease, intestinal parasites) or hereditary origin (i.e. sickle cell or thalassemia). Other possible but rarer causes have also been acknowledged [42]. Cribra frequency in Velia is $28.4 \%(\mathrm{~N}=74)$ with no differences between sexes. The combined data of diet

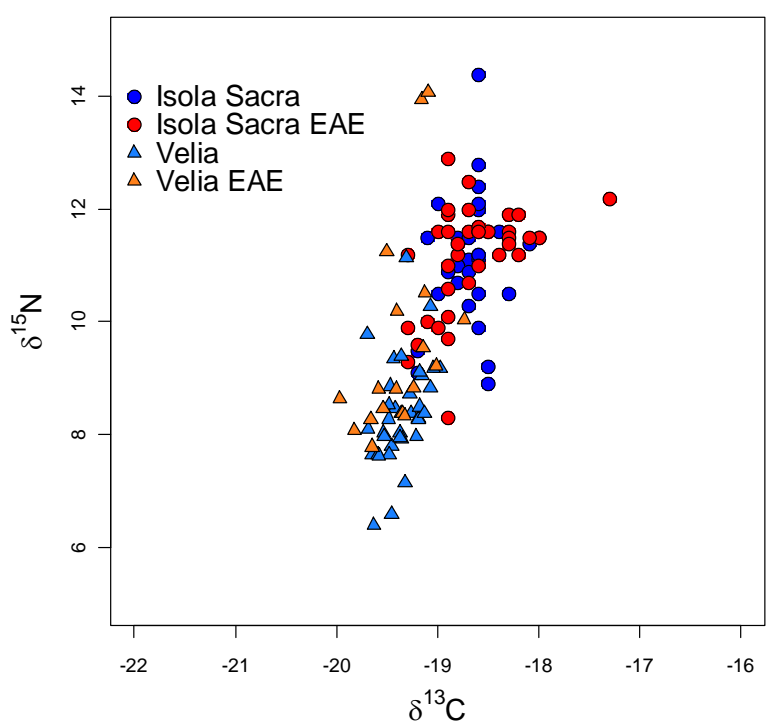

Figure 5. $\delta^{15} \mathrm{~N}$ and $\delta^{13} \mathrm{C}$ values and presence of the external auricular exostosis (EAE).

and cribra (Figure 6) point out that the individuals showing the highest $\delta^{15} \mathrm{~N}$ values do not present the lesions, while for the lower values both affected and unaffected individuals are equally represented. Overall, cribra and diet are not correlated at a level significantly different from zero.

\subsection{Velia: diet and DISH}

Diffuse idiopathic skeletal hyperostosis (DISH) is a pathological condition characterized by vertebral ankylosis and extraspinal bone proliferations. DISH has a complex etiology: it is often found associated with different metabolic disorders and it is more frequent in aged males. In the Velia male sample, the occurrence of DISH is rather high $(12.5 \%$; $=48)$, when compared with other archeological series [43], and significantly correlates with high $\delta^{15} \mathrm{~N}$ values (Figure 7), thus contributing with positive results to the issue of the possible influence of nutritional habits in the onset and manifestation of the pathology [44], [45].

\subsection{Velia and Isola Sacra: health status and weaning}

Histomorphometrical analysis of the dental crowns was performed in a subsample of 79 subadults from Velia and

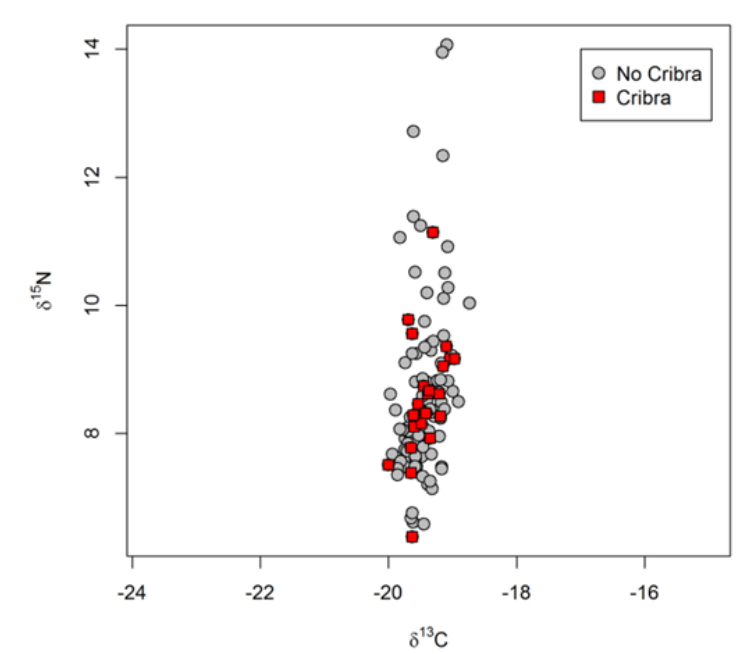

Figure 6. Velia: Nitrogen and Carbon isotopic delta values and presence of cribra orbitalia. 


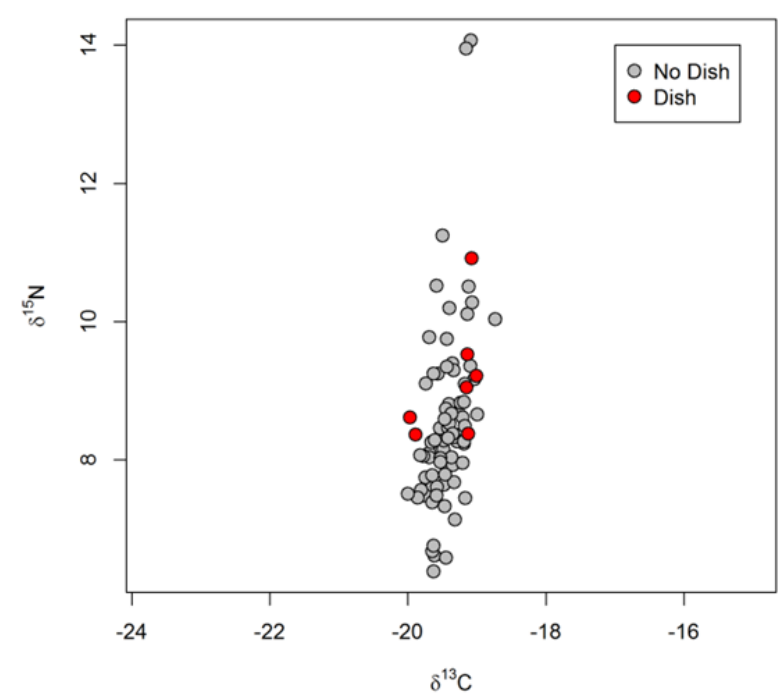

Figure 7. Velia: Nitrogen and Carbon isotopic delta values and presence of DISH.

compared with the results obtained from the histology of 127 deciduous teeth from the Isola Sacra sample [46].

Figure 8 shows the monthly prevalence distribution of the defects in both Velia and Isola Sacra. In both samples, the general trend of the curve is comparable, and shows a steep rise in months 1-5 possibly related, as expectable, to the decline of the maternal buffer. The higher monthly prevalence values observed in Isola Sacra suggest worst general health conditions during infancy, that could be related to a much broader range of the socio-economic status in reference to the smaller and more homogeneous Velian community.

Such kind of morbility trends is usually associated with the stress of weaning; however, the maximum peak in Velia seems to occur too early to be consistently explained with this hypothesis.

In Isola Sacra the high number of physiological stresses (ARL), registered from birth to 9 months, seems to do not affect the survivorship of children at later ages $(\mathrm{R}=-0.037)$. Similarly, the number of ARL does not consistently associate with diet (Figure 9).

\section{CONCLUSIONS}

The Carbon and Nitrogen stable isotope analysis depicts the dietary habits of Velia and Portus Romae communities, showing a high degree of variability in the diet composition,

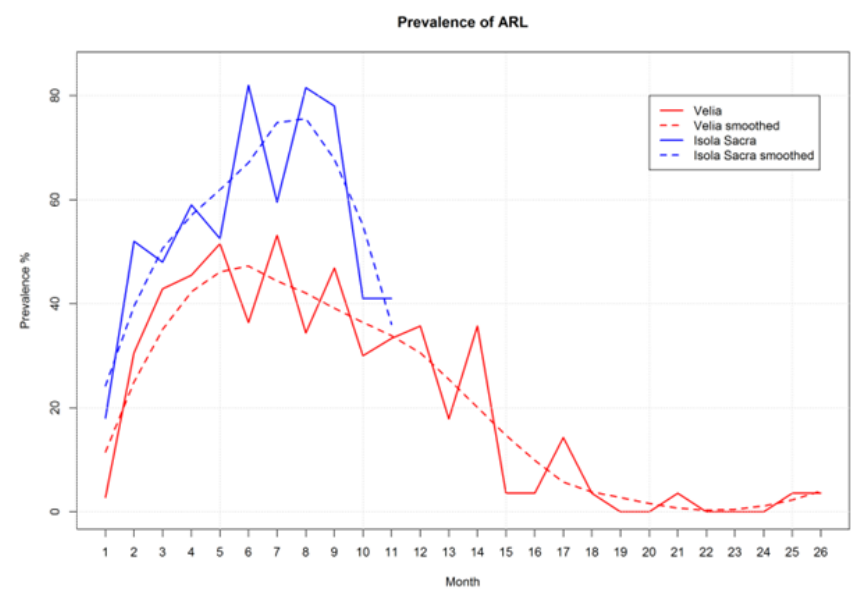

Figure 8. Maximum prevalence of stress events in Velia and Isola Sacra. especially regarding the levels of protein intake. Both samples show indication of marine food consumption. These evidences can be explained by the geographical location of the towns, together with the social complexity and differential subsistence strategies within the communities.

In the study of past populations, diet is usually considered a good proxy for wellbeing and it is usually presented and discussed as a standing alone evidence. Conversely we think that a more in-depth comprehension of ancient life conditions can be obtained through a strong historical and archeological contextualization and through the integration of data from multiple sources. Nevertheless, crossing stable isotope data with demographic, morphological and health parameters not always yields univocal results of simple and straightforward interpretation.

In fact, we found that Nitrogen delta values significantly correlates with a specific occupational activity (EAE), higher statures and the manifestation of a skeletal disorder (DISH), conversely the association of diet and aspecific stress indicators (ARL and cribra orbitalia) was not detected. Possible explanations can be suggested by the fact that cribra orbitalia, observed in the adult sample of Velia were developed during infancy and adolescence. However, recent calibrated studies on bone remodeling rates [47] suggest that the isotopic signal in the adult bone still reflects most of its later infancy, adolescence and early adulthood.

The absence of correlation between diet and ARL in the growing segment of Isola Sacra deserves further consideration and analysis, since it goes straight to the issue of the differential (and hidden) frailty of individuals and its influence in their morbidity and mortality.

In conclusion, the identification of physiological stress events and processes (such as weaning), the quantification of timing of formation, maturation and tooth eruption, the reconstruction of the differential diet inter- and intrapopulation and its changes in the course of life, represent invaluable information, which allows to build models of adaptive strategies, migrations, health and growth in an ancient population. Since these events are recorded at the tissue level in varying degrees during growth, their measure allows to challenge (although not entirely) the Osteological Paradox, offering the unique opportunity to carry out a longitudinal and

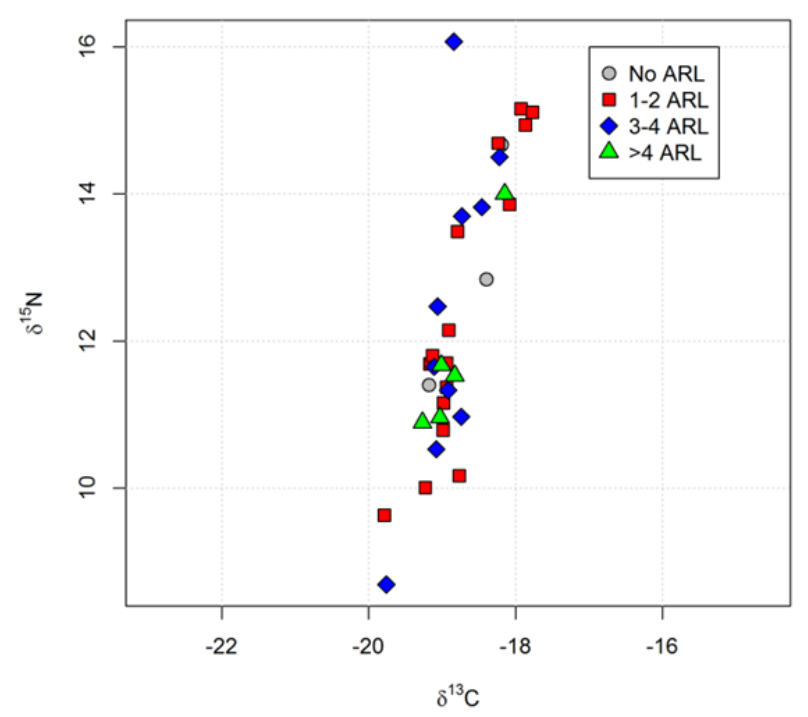

Figure 9. Isola Sacra Nitrogen and Carbon isotopic delta values and ARL number in the deciduous teeth analysed. 
transverse study of a mortality sample. The ultimate goal is to lay the basis for a (possible) consilience, or unity of knowledge, of history, archeology and anthropology.

\section{REFERENCES}

[1] J. Boquet-Appel, C. Masset, Farewell to paleodemography, J. Hum. Evol. 11 (1982) pp.321-333.

[2] J.W. Wood, G.R. Milner, H.C. Harpending, K.M. Weiss, The osteological paradox: problems of inferring prehistoric health from skeletal samples, Curr. Anthropol. 33 (1992) pp.343-358.

[3] W.M. Krogman, M.Y. Iscan, The Human Skeleton in Forensic Medicine, Charles C. Thomas, Springfield, 1986, ISBN 9780398052249

[4] M.K. Spradley, R.L. Jantz, Sex estimation in forensic anthropology: skull versus postcranial elements, J. For. Sci. 56 (2011) pp.289-296.

[5] G. Acsàdi, J. Nemeskéri, History of Human Life Span and Mortality, Akadémiai Kiadò, Budapest, 1970.

[6] C.O. Lovejoy, R.S. Meindl, R.P. Mensforth, T.J. Barton, Multifactorial determination of skeletal age at death: a method and blind test of its accuracy, Am. J. Phys. Anthropol. 68 (1985) pp.1-14.

[7] J.L. Boldsen, G.R. Milner, L.W. Konigsberg, J.W. Wood, "Transitional analysis: a new method for estimating age from skeletons", in: Paleodemography: Age Distributions from Skeletal Samples. R.D.Hoppa, J.W.Vaupel (editors). CUP, New York, 2002, ISBN 978-0-511-06326-8, pp.73-106.

[8] E.H. Kimmerle, D.A. Prince, G.E. Berg, Inter-observer variation in methodologies involving the pubic symphysis, sternal ribs, and teeth, J. For. Sci 53 (2008) pp.594-600.

[9] C.G. Falys, M.E. Lewis, Proposing a way forward: a review of standardisation in the use of age categories and ageing techniques in osteological analysis (2004-2009), Int. J. Osteoarch. 21 (2011) pp.704-716.

[10] H.M. Garvin, N.V. Passalacqua, Current practices by forensic anthropologists in adult skeletal age estimation, J. For. Sci.57 (2012) pp.427-433.

[11] J.E. Buikstra, D.H. Ubelaker, Standards for Data Collection from Human Skeletal Remains, Arkansas Archaeological Survey Research Series 44, Fayetteville, 1994, ISBN 978-1563490750.

[12] T.D. White, P.A. Folkens, Human Osteology, Academic Press, San Francisco, 1991, ISBN 978-0123741349.

[13] S.J. AlQahtani, Atlas of Human Tooth Development and Eruption, Queen Mary and Westfield College, 2009.

[14] M. Schaefer, S.M. Black, L. Scheuer, Juvenile Osteology: A Laboratory and Field Manual, Academic press, Amsterdam, 2009, ISBN, 978-0123746351.

[15] A. Mummert, E. Esche, J. Robinson, G.J. Armelagos, Stature and robusticity during the agricultural transition: evidence from the bioarchaeological record, Econ. Hum. Biol. 9 (2011) pp.284-301.

[16] M. Trotter, G.G. Gleser, Estimation of stature from long bones of American whites and negroes, Am. J. Phys. Anthropol.10 (1952) pp.463-514.

[17] M. Trotter, G.G. Gleser, A re- evaluation of estimation of stature based on measurements of stature taken during life and of long bones after death, Am. J. Phys. Anthropol.16 (1958) pp.79-123.

[18] K. Pearson, On the reconstruction of the stature of prehistoric races. Mathematic contributions to the theory of evolution, Philos. Trans. R. Soc.192 (1899) pp.169-244.

[19] L. Manouvrier, La détermination de la taille d'apré les grands os des membres, Mém. Soc. Anthropol. Paris 4 (1893) pp.347-402.

[20] S.D. Ousley, "Estimating stature", in: A Companion to Forensic Anthropology. D.D.Dirkmaat, Wiley-Blackwell, 2012, ISBN 9781-4051-9123-4, pp.330-334.

[21] M. Giannecchini, I. Moggi Cecchi, Stature in archaeological samples from central Italy: methodological issues and diachronic changes, Am. J. Phys. Anthropol.135 (2008) pp.284-292.

[22] R. Martin, K. Saller, Lehrbuch der Anthropologie, Band II, Stuttgart, Fischer, 1959.
[23] J.L. Boldsen, G.R. Milner, "An epidemiological approach to paleopathology", in: A Companion to Paleopathology. A.L.Grauer (editor). Wiley-Blackwell, Malden, MA., 2012, ISBN 978-1-4443-3425-8, pp.114-132.

[24] M.K. Zuckerman, B.L. Turner, G.J. Armelagos, "Evolutionary thought in paleopathology and the rise of the biocultural approach", in: A Companion to Paleopathology. A.L.Grauer (editor), Wiley-Blackwell, Malden, MA., 2012, ISBN 978-1-44433425-8, pp.34-57.

[25] M.K. Zuckerman, K.N. Harper, G.J. Armelagos, Adapt or die: three case studies in which the failure to adopt advances from other fields has compromised paleopathology, Int. J. Osteoarch, (2015) DOI: 10.1002/oa.2426.

[26] R. Macchiarelli, L. Bondioli, L. Censi, M. Kristoff, L. Salvadei, A. Sperduti, Intra and inter-osberver differences in direct and radiographic recording of tibial Harris' lines, Am. J. Phys. Anthropol. 95 (1994) pp.77-83.

[27] K.P. Jacobi, M.E. Danforth, Analysis of interobserver scoring patterns in porotic hyperostosis and cribra orbitalia, Int. J. Osteoarchaeol. 12 (2002) pp.248-258.

[28] A.L. Grauer (editor), A Companion to Paleopathology, WileyBlackwell, Malden, MA, 2012, ISBN 978-1-4443-3425-8.

[29] D.J. Reid, M.C. Dean, Variation in modern human enamel formation times, J. Hum. Evol.50 (2006) pp.329-346.

[30] F. Crowe, A. Sperduti, T. O'connel, O. Craig, K. Kirsanow, P. Germoni, R. Macchiarelli, P. Garnsey, L. Bondioli, Water-related occupations and diet in two Roman coastal communities (Italy, First to Third Century AD): Correlation between stable Carbon and Nitrogen isotope values and auricular exostosis prevalence, Am. J. Phys. Anthropol.142 (2010) pp.355-366.

[31] M.C. Dean, Growth layers and incremental markings in hard tissues: a review of the literature and some preliminary observations about enamel structure in Paranthropus boisei, J. Hum. Evol.16 (1987) pp.157-172.

[32] D.F. Wilson, F.R. Shroff, The nature of the striae of Retzius as seen with the optical microscope, Australian Dent. J.15 (1970) pp.162-171.

[33] C. Zanolli, L. Bondioli, F. Manni, P. Rossi, R. Macchiarelli, Gestation length, mode of delivery, and Neonatal Line thickness variation, Hum. Biol. 83, Iss.6, Art.8 (2011).

[34] N. Sabel, C. Johansson, J. Kuhnisch, A. Robertson, F. Steiniger, J.G. Norén, Neonatal lines in the enamel of primary teeth. A morphological and scanning electron microscopic investigation, Arch. Or. Biol. 53 (2008) pp.954-63.

[35] W. Birch, M.C. Dean, A method of calculating human deciduous crown formation times and of estimating the chronological ages of stressful events occurring during deciduous enamel formation, J. For. Leg. Med. 22 (2014) pp.127-144.

[36] D. Guatelli-Steinberg, B.A. Floyd, M.C. Dean, D.J. Reid, Enamel extension rate patterns in modern human teeth: two approaches designed to establish an integrated comparative context for fossil primates, J. Hum. Evol. 63 (2012) pp.475-486.

[37] S. Caropreso, L. Bondioli, D. Capannolo, Thin sections for hard tissues histology: a new procedure, J. Microsc. 199 (2000) pp.244247.

[38] P. Thévenaz, M. Unser, User-friendly semiautomated assembly of accurate image mosaics in microscopy, Microsc. Res. Tech. 70(2) (2007) pp.135-146.

[39] T. Prowse, H.P. Schwarcz, S. Saunders, R. Macchiarelli, L. Bondioli, Isotopic paleodiet studies of skeletons from the Imperial Roman-age cemetery of Isola Sacra, Rome, Italy, J. Arch. Sc.31 (2004) pp.259-272.

[40] F. Crowe, A. Sperduti, T.C. O'Connell, O.E. Craig, K. Kirsanow, P. Germoni, R. Macchiarelli, P. Garnsey, L. Bondioli, Waterrelated occupations and diet in two Roman coastal communities (Italy, first to third century AD): correlation between stable carbon and nitrogen isotope values and auricular exostosis prevalence, Am. J. Phys. Anthropol. 142 (2010) pp.355-366.

[41] O.E. Craig, M. Biazzo, T.C. O'Connell, P. Garnsey, C. MartinezLabarga, R. Lelli, L. Salvadei, G. Tartaglia, A. Nava, L. Renò, A. 
Fiammenghi, O. Rickards, L. Bondioli, Stable isotopic evidence for diet at the Imperial Roman coastal site of Velia (1st and 2nd centuries AD) in Southern Italy, Am. J. Phys. Anthropol. 139 (2009) pp.572-583.

[42] P.L. Walker, R.R. Bathurst, R. Richman, T. Gjerdrum, V.A. Andrushko, The causes of porotic hyperostosis and cribra orbitalia: a reappraisal of the iron-deficiency-anemia hypothesis, Am. J. Phys. Anthropol. 139 (2009) pp.109-125.

[43] R.K. Spencer, Testing hypotheses about diffuse idiopathic skeletal hyperostosis (DISH) using stable isotope and aDNA analysis of late medieval British populations, Durham theses, Durham University, 2008.

[44] M. Gundula, M.P. Richards, Diet and diversity at later medieval Fishergate: the isotopic evidence, Am. J. Phys. Anthropol. 134 (2007) pp.162-174.
[45] K. Quintelier, A. Ervynck, G. Müldner, W. Van Neer, M.P. Richards, B.T. Fuller, Diet and diversity at later medieval Fishergate: the isotopic evidence, Am. J. Phys. Anthropol. 153 (2014) pp.203-213.

[46] C. FitzGerald, S. Sauders, L. Bondioli, R. Macchiarelli, Health of infants in an Imperial Roman Skeletal sample: perspective from dental microstructure, Am. J. Phys. Anthropol. 189 (2006) pp.179-189.

[47] R. Hedges, J. Clement, C. Thomas, T. O'Connell, Collagen turnover in the adult femoral mid-shaft: modeled from anthropogenic radiocarbon tracer measurements, Am. J. Phys. Anthropol. 133 (2007) pp.808-816. 